\title{
Racial disparities in surgical management and outcomes of acute limb ischemia in the United States ${ }^{\frac{1}{3}}$
}

\author{
Matthew Gandjian, MD ${ }^{\mathrm{a}, \mathrm{b}}$, Sohail Sareh, MD ${ }^{\mathrm{a}, \mathrm{b}}$, Alykhan Premji, MD ${ }^{\mathrm{a}}$, Ramsey Ugarte, MD ${ }^{\mathrm{b}}$, Zachary Tran, MD $^{\mathrm{a}}$, \\ Nina Bowens, MD $^{\mathrm{b}}$, Peyman Benharash, MD ${ }^{\mathrm{a}, *}$ \\ a Cardiovascular Outcomes Research Laboratories (CORELAB), David Geffen School of Medicine at UCLA, Los Angeles, CA \\ ${ }^{b}$ Department of Surgery, Los Angeles County Harbor-UCLA Medical Center, Torrance, CA
}

\section{A R T I C L E I N F O}

\section{Article history:}

Received 1 May 2021

Received in revised form 22 August 2021

Accepted 27 August 2021

Available online 10 September 2021

\begin{abstract}
A B S T R A C T
Background: Although significant racial disparities in the surgical management of lower extremity critical limb threatening ischemia have been previously reported, data on disparities in lower extremity acute limb ischemia are lacking.

Methods: The 2012-2018 National Inpatient Sample was queried for all adult hospitalizations for acute limb ischemia $(N=225,180)$. Hospital-specific observed-to-expected rates of major lower extremity amputation were tabulated. Multivariable logistic and linear models were developed to assess the impact of race on amputation and revascularization.

Results: Nonwhite race was associated with significantly increased odds of overall (adjusted odds ratio: 1.16, 95\% confidence interval 1.06-1.28) and primary (adjusted odds ratio: 1.34, 95\% confidence interval 1.17-1.53) major amputation, decreased odds of revascularization (adjusted odds ratio $0.79,95 \%$ confidence interval 0.73-0.85), but decreased in-hospital mortality (adjusted odds ratio: $0.86,95 \%$ confidence interval $0.74-0.99$ ). The nonwhite group incurred increased adjusted index hospitalization costs $(\beta:+\$ 4,810,95 \%$ confidence interval 3,280-6,350), length of stay ( $\beta$ : +1.09 days, 95\% confidence interval 0.70-1.48), and nonhome discharge (adjusted odds ratio: $1.15,95 \%$ confidence interval 1.06-1.26).

Conclusion: Significant racial disparities exist in the management of and outcomes of lower extremity acute limb ischemia despite correction for variations in hospital amputation practices and other relevant hospital and patient characteristics. Whether the etiology lies primarily in patient, institution, or healthcare provider-specific factors has not yet been determined. Further studies of race-based disparities in management and outcomes of acute limb ischemia are warranted to provide effective and equitable care to all.
\end{abstract}

(c) 2021 The Author(s). Published by Elsevier Inc. This is an open access article under the CC BY-NC-ND license

(http://creativecommons.org/licenses/by-nc-nd/4.0/).

\section{INTRODUCTION}

Acute limb ischemia (ALI) remains a burdensome surgical emergency that is associated with a $22 \%$ risk of limb loss at 1 year [1]. With increasing adoption of more aggressive limb salvage strategies, variable treatment options ranging from traditional open methods to modern endovascular techniques are now within the surgeon's armamentarium. Significant racial and socioeconomic disparities in limb salvage rates for acute and chronic ischemia have been previously noted. In a recent analysis of the Vascular Quality Initiative database, O'Donnell et al

is Accepted for oral presentation at the 16th annual Academic Surgical Congress, February 2-4, 2021

* Corresponding author at: Division of Cardiac Surgery, UCLA David Geffen School of Medicine, CHS 62-249, 10833 Le Conte Ave, Los Angeles, CA, 90095.

E-mail address: pbenharash@mednet.ucla.edu (P. Benharash). reported inferior long-term outcomes and higher amputation rates among Black patients with limb ischemia as compared to their white counterparts [2]. Furthermore, Loja and colleagues identified significantly worse midterm outcomes among nonwhite patients undergoing endovascular management of peripheral vascular disease [3].

Although disease severity has been cited to explain the observed racial disparities [4,5], several authors have acknowledged reduced access to both acute and longitudinal care among socioeconomically disadvantaged minorities [5-7]. Loehrer and colleagues found expanded insurance coverage in the State of Massachusetts to reduce differences between white and nonwhite patients in specific outcomes such as rates of revascularization and amputation [8]. Although hospital-level variation in practice has been recently suggested to contribute to the observed disparities [9], in-depth analysis of socioeconomic factors in outcomes of ALI is lacking. The present study examined the potential association of race with clinical management of patients with acute limb ischemia in a national cohort. We further examined the impact of 
hospital-level variation on race-based outcomes of ALI including amputation, length of stay, and inpatient hospitalization costs. We hypothesized nonwhite minorities to face higher rates of primary amputation without attempted revascularization despite risk adjustment.

\section{METHODS}

This was a retrospective analysis of the 2012-2018 National Inpatient Sample (NIS) to identify all nonelective hospitalizations with a diagnosis of lower extremity acute limb ischemia. Part of the Healthcare Cost and Utilization Project, the NIS is the largest all-payer publicly available database and provides accurate estimates for $97 \%$ of all US hospitalizations using stratified survey weights [10]. Specific International Classification of Diseases, Ninth and Tenth Edition diagnostic and procedural codes (ICD-9/ICD-10) were used to identify hospitalizations for acute limb ischemia, revascularization procedures, and major lower extremity amputation (MLA) using previously validated codes when available [11-13] (Supplemental Table 1). Time from admission to revascularization or MLA was tabulated using the "PRDAY" variable in the NIS ${ }^{10}$. Patients $<18$ years of age and those missing key information such as sex, age, income, race, or mortality were excluded (8.0\%). Hospitalizations with codes (Supplemental Table 1) for history of prior revascularization (1.5\%) as well as hypotension and severe sepsis (8.3\%) were also excluded to minimize heterogeneity of the sample. In such cases, primary amputation may have been necessary.

Patient and hospital characteristics of interest included age, sex, race, hospital teaching status, bed size, and geographic region, among others (Table 1). Subjects were classified as "white" according to selfdeclared race as indicated, whereas all other race categories were considered "nonwhite." Comorbidities were ascertained using relevant ICD-9/10-CM codes [14]. The previously validated Elixhauser Comorbidity Index was used to quantify the burden of chronic conditions [15]. Costs were calculated by application of center-specific cost-to-charge ratios to aggregate hospitalization charges and inflation adjusted to the 2017 Personal Health Care Index [16].

The primary outcomes of interest were primary (without revascularization attempt) and overall MLA excluding the toe and the forefoot in accordance with prior studies [7,9,17-20]. Secondary outcomes included time from admission to revascularization or amputation, mortality at index hospitalization, costs, length of stay (LOS), and rates of nonhome discharge. Significance of temporal trends was determined using Cuzick's rank-based nonparametric test (NPtrend) [21]. Categorical and continuous variables were compared using $\chi^{2}$ and adjusted Wald tests, respectively. Multivariable logistic and linear models were developed to identify independent association of covariates with outcomes of interest. Clinically relevant covariates, including patient and hospital characteristics and revascularization strategy (open, endovascular, or a hybrid approach), were subjected to least absolute shrinkage selection operator [22] selection. This regularization method enhances accuracy and out-of-sample reliability of prediction models while reducing collinearity and the number of explanatory variables. Transfer status and presence of gangrene (Supplemental Table 1) were included as covariates to ensure appropriate risk adjustment. Receiver operating characteristics ( $C$ statistic) [23] as well as the Akaike and Bayesian Information Criteria were used to optimize model selection [24].

To characterize hospital-level variations in management of ALI, a regression model using patient-level covariates was developed to predict odds of MLA. Aggregated values were used to create hospital-level expected amputation rates. Normalization of the observed hospital-level amputation rate for ALI by the expected rate yielded average hospitalspecific observed-to-expected (O/E) ratios.

All data analyses were performed using Stata 16 (StataCorp. 2019, College Station, TX). Categorical variables are reported as proportions (\%) and continuous variables as means with standard deviations (SDs) or medians with interquartile range (IQR) if not normally distributed.
Table 1

Patient and hospital demographics and characteristics

\begin{tabular}{|c|c|c|c|}
\hline & $\begin{array}{l}\text { White } \\
(\mathrm{N}=164,285)\end{array}$ & $\begin{array}{l}\text { Nonwhite } \\
(\mathrm{N}=60,895)\end{array}$ & $\begin{array}{l}\mathrm{P} \\
\text { value }\end{array}$ \\
\hline Age, mean (SD) & $67.8(14.5)$ & $63.8(15.5)$ & $<.001$ \\
\hline Female (\%) & 42.9 & 44.6 & .001 \\
\hline Income percentile (\%) & & & $<.001$ \\
\hline 76-99th & 19.0 & 13.1 & \\
\hline $51-75$ th & 24.3 & 18.0 & \\
\hline 26-50th & 28.7 & 22.0 & \\
\hline $0-25$ th & 28.0 & 46.9 & \\
\hline Primary payer (\%) & & & $<.001$ \\
\hline Private insurance & 19.3 & 16.0 & \\
\hline Medicare & 64.0 & 55.5 & \\
\hline Medicaid & 9.7 & 19.1 & \\
\hline Other pay & 6.9 & 9.4 & \\
\hline Location/teaching status (\%) & & & $<.001$ \\
\hline Nonmetropolitan & 5.8 & 2.3 & \\
\hline Metropolitan nonteaching & 27.0 & 21.2 & \\
\hline Metropolitan teaching & 67.2 & 76.4 & \\
\hline Hospital region (\%) & & & $<.001$ \\
\hline Northeast & 19.9 & 18.4 & \\
\hline Midwest & 23.1 & 14.7 & \\
\hline South & 39.5 & 45.8 & \\
\hline West & 17.5 & 21.1 & \\
\hline Hospital bed size (\%) & & & .61 \\
\hline Large & 62.2 & 61.7 & \\
\hline Medium & 26.0 & 26.6 & \\
\hline Small & 11.9 & 11.7 & \\
\hline Operative approach (\%) & & & $<.001$ \\
\hline Endovascular & 27.0 & 26.5 & \\
\hline Open & 27.9 & 24.6 & \\
\hline Hybrid & 10.6 & 9.3 & \\
\hline No revascularization & 34.5 & 39.6 & \\
\hline Transferred from other hospital (\%) & 18.7 & 12.2 & $<.001$ \\
\hline Gangrene (\%) & 5.8 & 8.8 & $<.001$ \\
\hline \multicolumn{4}{|l|}{ Comorbidities (\%) } \\
\hline Anemia & 3.4 & 4.3 & $<.001$ \\
\hline Coronary artery disease & 35.2 & 31.6 & $<.001$ \\
\hline Cardiac arrhythmias & 34.1 & 26.5 & $<.001$ \\
\hline Congestive heart failure & 24.3 & 25.7 & .002 \\
\hline Chronic lung disease & 26.9 & 18.6 & $<.001$ \\
\hline Coagulopathy & 8.8 & 9.1 & .46 \\
\hline Diabetes & 28.8 & 59.9 & $<.001$ \\
\hline Electrolyte disorder & 27.5 & 28.9 & .003 \\
\hline Elixhauser, mean (SD) & $3.7(1.8)$ & $3.8(1.8)$ & $<.001$ \\
\hline End-stage renal disease & 4.6 & 10.3 & $<.001$ \\
\hline Hypertension & 65.8 & 71.6 & $<.001$ \\
\hline Late chronic kidney disease & 3.3 & 8.9 & $<.001$ \\
\hline Liver disease & 3.6 & 4.0 & .06 \\
\hline Pulmonary circulation disorder & 6.0 & 6.4 & .12 \\
\hline Peripheral vascular disease & 53.0 & 51.6 & .01 \\
\hline $\begin{array}{l}\text { Rheumatoid arthritis/collagen } \\
\text { vascular disease }\end{array}$ & 3.1 & 3.3 & .26 \\
\hline Tobacco use disorder & 42.1 & 37.0 & $<.001$ \\
\hline Valvular disease & 7.5 & 6.0 & $<.001$ \\
\hline Weight loss & 8.8 & 8.9 & .73 \\
\hline
\end{tabular}

Results of logistic and linear models are reported as adjusted odds ratios (AORs) and beta coefficients ( $\beta \mathrm{s}$ ) with 95\% confidence intervals (95\% CIs), respectively. The study was deemed exempt from full review by the Institutional Review Board at the University of California, Los Angeles.

\section{RESULTS}

Trends and Patient-Level Factors. Of an estimated 225,180 nonelective admissions for lower extremity ALI, 27.0\% were nonwhite. Revascularization was performed in $64.1 \%$ of admissions: $42.1 \%$ open, $42.0 \%$ endovascular, and $16.0 \%$ hybrid. Utilization of the endovascular approach increased significantly from $39.7 \%$ in 2012 to $44.5 \%$ of cases in 2018 (NPtrend < .001). A comparison of characteristics by race is shown in Table 1. Compared to white patients, those in the nonwhite 
Table 2

Unadjusted comparison of white and nonwhite patient outcomes

\begin{tabular}{llll}
\hline & $\begin{array}{l}\text { White } \\
(\mathrm{N}=164,285)\end{array}$ & $\begin{array}{l}\text { Nonwhite } \\
(\mathrm{N}=60,895)\end{array}$ & $\begin{array}{l}\mathrm{P} \\
\text { value }\end{array}$ \\
\hline Major amputation, \% & 6.6 & 8.7 & $<.001$ \\
Revascularization attempt, \% & 65.5 & 60.4 & $<.001$ \\
Primary amputation, \% & 2.9 & 4.5 & $<.001$ \\
Time to revascularization, mean (SD), d & $2.1(3.4)$ & $2.8(4.0)$ & $<.001$ \\
Time to amputation, mean (SD), d & $6.8(7.4)$ & $8.3(8.9)$ & $<.001$ \\
Mortality, \% & 6.3 & 5.3 & $<.001$ \\
Costs, median (IQR), \$1,000 & $22.4(12.8-37.9)$ & $24.9(14.1-43.9)$ & $<.001$ \\
LOS, median (IQR), d & $6(3-10)$ & $7(4-12)$ & $<.001$ \\
Nonhome discharge, \% & 54.5 & 55.0 & .40 \\
\hline
\end{tabular}

cohort were on average younger, were more likely to suffer from diabetes and several other comorbidities, belonged to the lowest income quartile, and were uninsured or carried Medicaid insurance, as shown in Table 1 (all $P<.001$ ). Nonwhite hospitalizations had a higher incidence of gangrene and were more likely to be at rural hospitals (Table 1). Conversely, white hospitalizations more frequently included a diagnosis of coronary artery disease and cardiac arrhythmias.

Unadjusted rates of MLA among both white (6.3\% in 2012 to $6.0 \%$ in 2018, NPtrend .03) and nonwhite (10.2\% in 2012 to $7.9 \%$ in 2018 , NPtrend $<.001$ ) decreased significantly over the study period. Compared to white patients, the nonwhite group experienced significantly higher unadjusted rates of MLA ( $8.7 \%$ vs $6.6 \%$ ) and primary amputation ( $4.5 \%$ vs $2.9 \%$ ) but lower utilization of revascularization (60.4\% vs $65.5 \%$, all $P<.001$ ) (Table 2). After adjusting for differences in patient and hospital characteristics, several factors were associated with increased odds of MLA and included open or hybrid intervention, weight loss, diabetes, and coagulopathy, among others, as shown in Supplemental Table 2. Importantly, nonwhite race was associated with 1.11 -fold (95\% CI 1.01-1.21) odds of MLA prior to adjustment for center specific O/E ratios. Nonwhite race was associated with increased time from admission to revascularization or MLA on both unadjusted and adjusted analyses compared to the white cohort (Table 2). The plot of risk-adjusted major amputation over the study years demonstrated similar racebased disparities (Fig 1).

Hospital-Level Variation and Access. Evaluation of center-specific O/E ratios for MLA demonstrated a wide variation among hospitals as shown in Figure 2 . Nearly $86.7 \%$ of hospitals had O/E ratios of greater than 1, indicating higher-than-anticipated use of MLA based on patient factors alone. These centers treated $63.5 \%$ of hospitalizations with ALI. Nonwhite race was associated with a 1.19-fold (95\% CI 1.09-1.28)

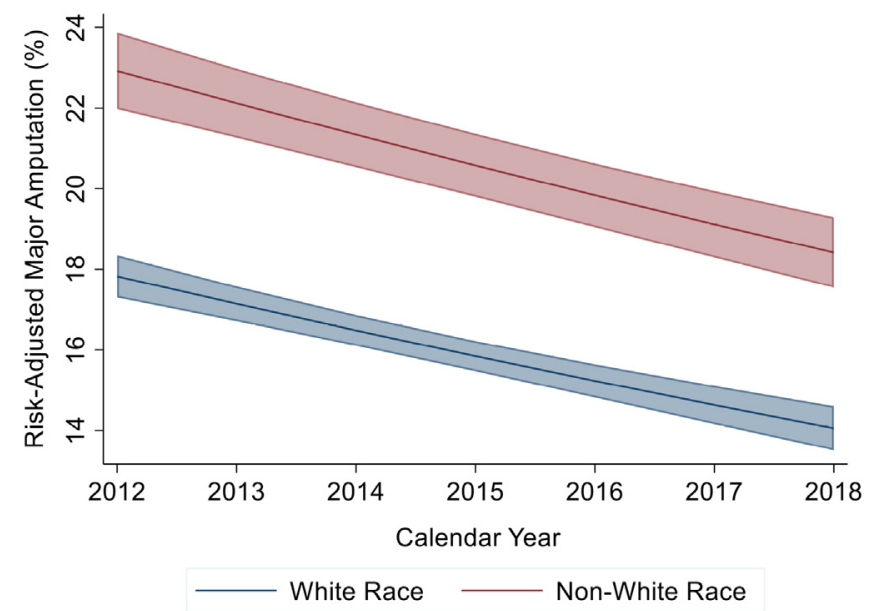

Fig 1. Trends of risk-adjusted comparison of white and nonwhite major amputation.

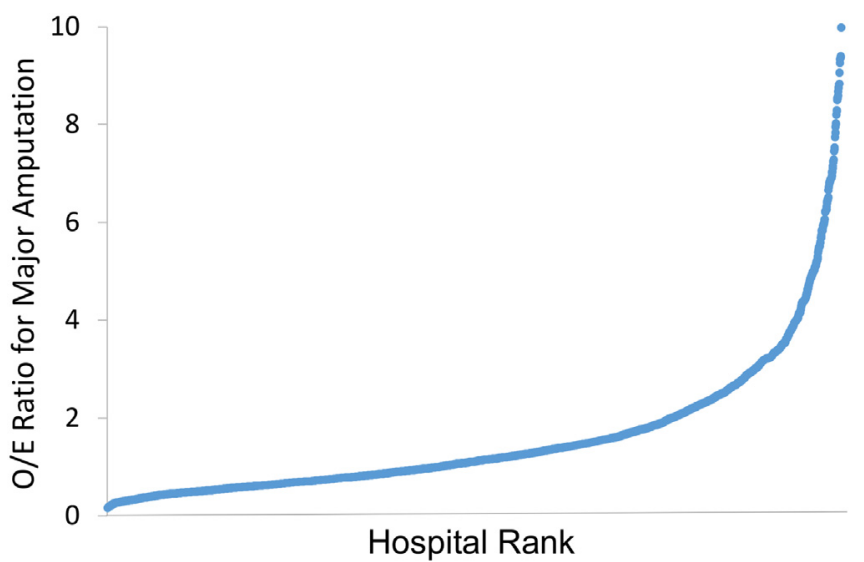

Fig 2. Plot of hospital major amputation observed-to-expected ratios for acute limb ischemia.

increased odds of treatment at hospitals with $\mathrm{O} / \mathrm{E}>1$. After further adjustment for hospital O/E ratios, nonwhite race among other factors (Table 3 ) remained associated with significantly higher odds of MLA, lower odds of revascularization, higher odds of primary amputation, and increased delay to amputation and revascularization (Table 4). Risk-adjusted MLA over hospital O/E ratios is shown in Figure 3 and demonstrated persistently higher predicted odds for the nonwhite cohort. Furthermore, risk-adjusted MLA as a function of days to revascularization attempt demonstrated higher odds of amputation among nonwhites compared to whites up to 8 days after admission (Fig 4).

Interestingly, nonwhite race was associated with decreased odds of mortality compared to white (AOR $0.86,95 \%$ CI 0.74-0.99). Furthermore, although nonwhite hospitalizations were less frequently transferred from outside institutions (Table 1), transfer status was associated with significantly increased risk of major amputation (Table 3).

Metrics of Resource Utilization. On both crude (Table 2) and riskadjusted (Table 4) comparisons, costs and LOS were significantly higher among nonwhite hospitalizations (ref: white). Nonwhite classification was associated with increased adjusted odds of nonhome discharge (Table 4). Major amputation was associated with a nearly $\$ 17,800$ increment in adjusted index hospitalization costs (95\% CI \$16,049$\$ 19,580, P<.001)$. Risk-adjusted hospitalization costs stratified by procedure type are shown in Table 5 and demonstrate persistently increased costs among nonwhite hospitalizations compared to white, irrespective of the type of treatment.

\section{DISCUSSION}

Once the mainstay of therapy for ischemic limbs, primary amputation has been supplanted by revascularization attempts in select patients to avert limb loss. However, limb salvage requires additional expertise and may not be uniformly utilized across health systems. In the present population-based study of hospitalizations with acute limb ischemia, we have demonstrated significant race-based disparities in treatment strategy and outcomes. Nonwhite race is associated with increased risk-adjusted odds of major amputation but lower likelihood of revascularization. Once admitted, nonwhites experienced increased delay to revascularization or amputation procedures. Significant interhospital variations with regard to likelihood of amputation exist. Nonwhite hospitalizations were more likely to be at facilities with higherthan-expected amputation rates. Several of these findings warrant further discussion.

Our analysis demonstrated nonwhite race to be associated with not only significantly increased major amputation but also increased 
Table 3

Factors associated with major amputation in multivariable model $(C$ statistic $=0.80)$

\begin{tabular}{|c|c|c|c|}
\hline & $A O R$ & $95 \% C I$ & P value \\
\hline White race & Ref & & \\
\hline Nonwhite race & 1.16 & $1.06-1.28$ & .002 \\
\hline Age (per year increment) & 1.00 & $0.99-1.00$ & .30 \\
\hline Female sex & 0.90 & $0.82-0.99$ & .02 \\
\hline Hospital O/E ratio (per increment of 1 ) & 4.96 & $4.62-5.32$ & $<.001$ \\
\hline \multicolumn{4}{|l|}{ Income percentile } \\
\hline 76-99th & Ref & & \\
\hline $51-75$ th & 1.12 & $0.98-1.30$ & .11 \\
\hline 26-50th & 1.15 & $1.00-1.32$ & .04 \\
\hline $0-25$ th & 1.43 & $1.26-1.62$ & $<.001$ \\
\hline \multicolumn{4}{|l|}{ Payer } \\
\hline Privately insured & Ref & & \\
\hline Medicare & 1.25 & $1.09-1.43$ & .002 \\
\hline Medicaid & 1.40 & $1.20-1.64$ & $<.001$ \\
\hline Other payer/uninsured & 0.89 & $0.73-1.08$ & .23 \\
\hline \multicolumn{4}{|l|}{ Location/teaching status } \\
\hline Metropolitan teaching & Ref & & \\
\hline Metropolitan nonteaching & 1.00 & $0.94-1.06$ & .93 \\
\hline Rural & 1.13 & $0.99-1.28$ & .06 \\
\hline \multicolumn{4}{|l|}{ Bed size } \\
\hline Large & Ref & & \\
\hline Medium & 1.03 & $0.97-1.09$ & .34 \\
\hline Small & 1.05 & $0.96-1.15$ & .30 \\
\hline \multicolumn{4}{|l|}{ Year } \\
\hline 2012 & Ref & & \\
\hline 2013 & 1.00 & $0.93-1.08$ & .93 \\
\hline 2014 & 1.00 & $0.93-1.08$ & .93 \\
\hline 2015 & 0.89 & $0.83-0.96$ & .004 \\
\hline 2016 & 0.81 & $0.74-0.89$ & $<.001$ \\
\hline 2017 & 0.79 & $0.72-0.87$ & $<.001$ \\
\hline 2018 & 0.70 & $0.64-0.77$ & $<.001$ \\
\hline Gangrene & 7.53 & $6.66-8.51$ & $<.001$ \\
\hline Transfer in from other institution & 1.30 & $1.17-1.45$ & $<.001$ \\
\hline \multicolumn{4}{|l|}{ Operative approach } \\
\hline Endovascular & Ref & & \\
\hline Open & 1.42 & $1.26-1.61$ & $<.001$ \\
\hline Hybrid & 1.81 & $1.56-2.11$ & $<.001$ \\
\hline No revascularization & 1.53 & $1.35-1.73$ & $<.001$ \\
\hline \multicolumn{4}{|l|}{ Comorbidities } \\
\hline Cardiac arrhythmia & 0.94 & $0.84-1.05$ & .30 \\
\hline Chronic lung disease & 0.91 & $0.81-1.03$ & .13 \\
\hline Coagulopathy & 1.34 & $1.17-1.55$ & $<.001$ \\
\hline Congestive heart failure & 1.00 & $0.89-1.12$ & .98 \\
\hline Coronary artery disease & 0.75 & $0.67-0.83$ & $<.001$ \\
\hline Diabetes & 1.31 & $1.18-1.46$ & $<.001$ \\
\hline Electrolyte disorders & 1.99 & $1.79-2.21$ & $<.001$ \\
\hline Elixhauser score (per 1 increment) & 0.99 & $0.95-1.03$ & .61 \\
\hline End-stage renal disease & 0.89 & $0.66-1.20$ & .45 \\
\hline Late-stage kidney disease & 1.36 & $1.00-1.86$ & .05 \\
\hline Liver disease & 0.96 & $0.77-1.20$ & .75 \\
\hline Pulmonary circulation disorder & 0.73 & $0.58-0.91$ & .005 \\
\hline Rheumatoid arthritis/collagen vascular disease & 1.99 & $1.60-2.48$ & $<.001$ \\
\hline Valvular disease & 0.58 & $0.46-0.73$ & $<.001$ \\
\hline Weight loss & 2.21 & $1.94-2.52$ & $<.001$ \\
\hline
\end{tabular}

primary amputation and lower likelihood of a revascularization attempt compared to hospitalizations of whites with ALI. These disparities existed even when adjusting for presence of gangrene, variations in

Table 4

Adjusted comparison of white and nonwhite outcomes

\begin{tabular}{lllll}
\hline & White & Nonwhite & $95 \%$ CI & P value \\
\hline Major amputation (AOR) & Ref & 1.16 & $1.06-1.28$ & .002 \\
Revascularization attempt (AOR) & Ref & 0.79 & $0.73-0.85$ & $<.001$ \\
Primary amputation (AOR) & Ref & 1.34 & $1.17-1.53$ & $<.001$ \\
Time to revascularization $(\beta), \mathrm{d}$ & Ref & +0.31 & $0.14-0.48$ & $<.001$ \\
Time to amputation $(\beta), \mathrm{d}$ & Ref & +0.75 & $0.14-1.37$ & .02 \\
Mortality (AOR) & Ref & 0.86 & $0.74-0.99$ & .048 \\
Costs $(\beta), \$ 1,000$ & Ref & +4.81 & $3.28-6.35$ & $<.001$ \\
LOS $(\beta), \mathrm{d}$ & Ref & +1.09 & $0.70-1.48$ & $<.001$ \\
Nonhome discharge (AOR) & Ref & 1.15 & $1.06-1.26$ & .001 \\
\hline
\end{tabular}

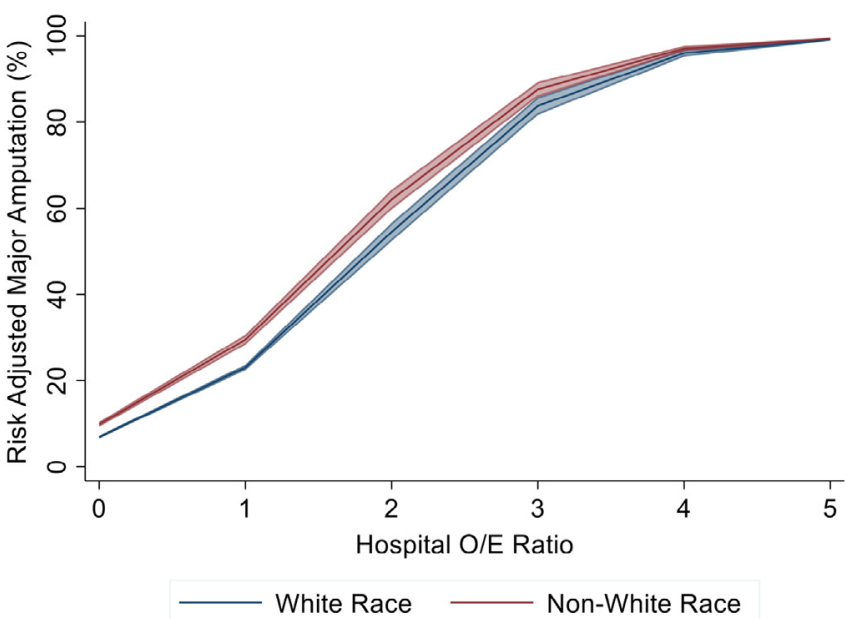

Fig 3. Risk-adjusted comparison of white and nonwhite race by hospital observed-toexpected ratio for major amputation.

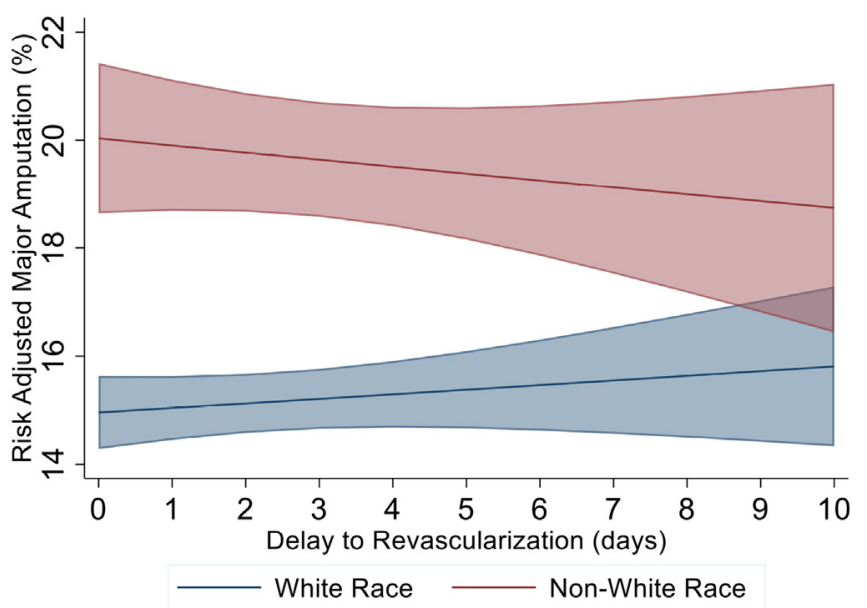

Fig 4. Risk-adjusted comparison of white and nonwhite race by delay to revascularization for major amputation.

hospital amputation practices, and other relevant patient and hospital factors. Although more advanced disease presentation likely played a major role in the disparate outcomes of ALI hospitalizations, the present analysis also identified increased procedural delays among nonwhites after admission. Among hospitalizations in which a revascularization procedure was attempted, nonwhite race was associated with a riskadjusted increase of nearly one third of a day from admission to revascularization as well as increased odds of major amputation after revascularization up to 8 days after admission. Such procedural delays may have contributed to the observed increased amputation among the nonwhite group, especially in the setting of a threatened limb. Nonwhite race was also associated with a procedural delay to MLA and may

Table 5

Adjusted comparison of white and nonwhite hospitalization costs by treatment modality

\begin{tabular}{lllll}
\hline & White & Nonwhite & $95 \% \mathrm{CI}$ & P value \\
\hline Primary amputation & Ref & $+\$ 5,087$ & $152-10,022$ & .04 \\
Angioplasty or stenting & Ref & $+\$ 4,424$ & $2,199-6,649$ & $<.001$ \\
Catheter-directed thrombolysis & Ref & $+\$ 4,899$ & $2,252-7,546$ & $<.001$ \\
Open thrombectomy & Ref & $+\$ 6,058$ & $1,967-10,148$ & .004 \\
Open bypass, replacement, or repair & Ref & $+\$ 7,991$ & $4,598-11,385$ & $<.001$ \\
\hline
\end{tabular}


have contributed to the observed increase in LOS and hospitalization costs. Furthermore, such increased costs among hospitalizations of nonwhites persisted irrespective of revascularization approach.

The present study identified great variability with regard to hospitallevel likelihood of amputation. Compared to the mean, some sampled hospitals in our study had nearly 10 -fold risk-stratified increased odds of amputation. These results are consistent with prior studies documenting regional variations in delivery of vascular care in the United States. While some have shown the South Atlantic and South Central regions to have higher rates of amputations and lower intensity of vascular care [25-29], others have demonstrated disproportionately greater likelihood of primary amputation among rural nonwhite groups [30]. Similarly, the current analysis found hospitalizations of nonwhites more likely to be at centers that exhibited greater-than-expected rates of amputation based on patient factors alone. Nevertheless, the present study employed multivariable models that controlled for hospital region and additionally used center-specific observed-to-expected MLA ratios to account for practice variation at each center. Persistent racial disparities were identified irrespective of such institutional variables. In contrast, nonwhite race was associated with decreased mortality in these multivariable models. Such a finding should come as a surprise because minorities, particularly black minorities, have consistently been found have increased operative mortality compared to whites after carotid endarterectomy, cardiac surgery, abdominal aortic aneurysm repair, and resection for lung cancer and pancreatic resection, among others [31]. One possible explanation of the decreased mortality among nonwhites with ALI is younger age, although the exact etiology is unable to be determined based on the present study.

Racial disparities are not isolated to outcomes of ALI in the realm of vascular surgery; in fact, our findings echo data from numerous prior studies of patients with chronic limb threatening ischemia, documenting minorities to be more likely to undergo major amputation $[9,12,18]$, have early graft failure after infrainguinal bypass [32], and receive a primary amputation without revascularization attempt [33]. Although few studies have specifically addressed the underlying etiology of these discrepancies, many putative factors have been proposed. Some authors have pointed to more advanced presentation due to poor access to care $[6,32,34,35]$ and therefore limited availability of proven preventive measures such as lipid-lowering and antiplatelet agents and smoking cessation among racial minorities [36-39]. For example, a recent study of the Veteran Health Administration Corporate Data Warehouse identified black patients with peripheral arterial disease to be less likely to have been prescribed statins or antiplatelet medications compared to white patients [18]. Although the natural history of chronic limb threatening ischemia is more insidious as compared to ALI, success in limb salvage for both disease processes is directly affected by disease severity, which may be a surrogate for longitudinal access to care. Inability to have regular medical care generally results in later and more severe presentation of the illness and does not allow for modification of disease course via lifestyle modifications and medications. Conversely, Durazzo et al have noted that racial disparities persist even when controlling for differences in access to care [33]. Authors who have studied racial variations in arterial phenotype have noted arteries of black populations to be stiffer compared to those of white persons even when controlling for age, mean arterial pressure, and body composition [40-42]. Others have called for further investigation of racespecific genetic differences related to disease behavior [43].

Our study has important limitations. First, this is a retrospective observational study, and despite use of robust multivariable and linear regression models to account differences in the 2 cohorts, there is the possibility that unknown covariates may have influenced outcomes resulting in residual confounding. Second, the NIS is an administrative database and findings are subject to potential coding inaccuracies. The present study used relevant ICD-9 and ICD-10 diagnostic and procedural codes that were previously validated whenever available [11-13]. Third, the NIS lacks information pertinent to clinical variables such as medication history, Rutherford class, etiology of ALI, symptom duration, anatomic considerations, and prior revascularization history. Lastly, given the administrative nature of the NIS database, we did not have data with respect to why revascularization was or was not offered, or whether or not patients refused such interventions.

Despite these limitations, we have demonstrated significant racebased disparities in the outcomes of hospitalizations with ALI. Although such observations are likely multifactorial in nature, our results suggest advanced disease and procedural delays to play a role. Although performance-based reimbursement strategies at the hospital level may lead to decreased procedural delays and improved quality of care after presentation, such policies will not serve to bridge the gap in disparate outcomes attributable to increased disease severity among minorities at the time of presentation. Thus, hospital-based improvement efforts must be paired with improved equality in access to care to enhance early detection as well as disease prevention among the socioeconomically disadvantaged.

\section{Author Contribution}

Matthew Gandjian: Conceptualization, Methodology, Software, Formal analysis, Writing - original draft. Sohail Sareh: Software, Formal analysis, Writing - review \& editing. Alykhan Premji: Writing - original draft. Ramsey Ugarte: Writing - original draft. Zachary Tran: Writing original draft. Nina Bowens: Conceptualization, Supervision. Peyman Benharash: Project administration, Supervision, Writing - review \& editing, Resources, Conceptualization.

\section{Conflict of Interest}

The authors declare no conflicts of interest.

\section{Funding Source}

The present work did not receive any funding.

\section{Appendix A. Supplementary data}

Supplementary data to this article can be found online at https://doi. org/10.1016/j.sopen.2021.08.003.

\section{References}

[1] Baril DT, Patel VI, Judelson DR, et al. Outcomes of lower extremity bypass performed for acute limb ischemia. Journal of Vascular Surgery. Mosby; 2013. p. 949-56. https://doi.org/10.1016/j.jvs.2013.04.036.

[2] O'Donnell TFX, Powell C, Deery SE, et al. Regional variation in racial disparities among patients with peripheral artery disease. J Vasc Surg. 2018;68(2):519-26. https://doi.org/10.1016/j.jvs.2017.10.090.

[3] Loja MN, Brunson A, Li CS, et al. Racial disparities in outcomes of endovascular procedures for peripheral arterial disease: an evaluation of California hospitals, 20052009. Ann Vasc Surg. 2015;29(5):950-9. https://doi.org/10.1016/j.avsg.2015.01.006.

[4] Rivero M, Nader ND, Blochle R, Harris LM, Dryjski ML, Dosluoglu HH. Poorer limb salvage in African American men with chronic limb ischemia is due to advanced clinical stage and higher anatomic complexity at presentation. J Vasc Surg. 2016;63(5): 1318-24. https://doi.org/10.1016/j.jvs.2015.11.052.

[5] Mustapha JA, Fisher BT, Rizzo JA, et al. Explaining racial disparities in amputation rates for the treatment of peripheral artery disease (PAD) using decomposition methods. J Racial Ethn Health Disparities. 2017;4(5):784-95. https://doi.org/10. 1007/s40615-016-0261-9.

[6] Eslami MH, Zayaruzny M, Fitzgerald GA. The adverse effects of race, insurance status, and low income on the rate of amputation in patients presenting with lower extremity ischemia. J Vasc Surg. 2007;45(1):55-9. https://doi.org/10.1016/j.jvs.2006. 09.044 .

[7] Traven SA, Synovec JD, Walton ZJ, Leddy LR, Suleiman LI, Gross CE. Notable racial and ethnic disparities persist in lower extremity amputations for critical limb ischemia and infection. J Am Acad Orthop Surg. 2020;28(21):885-92. https://doi.org/10. 5435/JAAOS-D-19-00630.

[8] Loehrer AP, Hawkins AT, Auchincloss HG, Song Z, Hutter MM, Patel VI. Impact of expanded insurance coverage on racial disparities in vascular disease insights from Massachusetts. Ann Surg. 2016;263(4):705-11. https://doi.org/10.1097/SLA. 0000000000001310. 
[9] Henry AJ, Hevelone ND, Belkin M, Nguyen LL. Socioeconomic and hospital-related predictors of amputation for critical limb ischemia. J Vasc Surg. 2011;53(2): 330-339.e1. https://doi.org/10.1016/j.jvs.2010.08.077.

[10] NIS database documentation. https://www.hcup-us.ahrq.gov/db/nation/nis/ nisdbdocumentation.jsp. [Accessed 17 January 2021].

[11] Kolte D, Kennedy KF, Shishehbor MH, et al. Endovascular versus surgical revascularization for acute limb ischemia: a propensity-score matched analysis. Circ Cardiovasc Interv. 2020;13(1). https://doi.org/10.1161/CIRCINTERVENTIONS.119. 008150.

[12] Baril DT, Ghosh K, Rosen AB. Trends in the incidence, treatment, and outcomes of acute lower extremity ischemia in the United States Medicare population. J Vasc Surg. 2014;60(3):669-677.e2. https://doi.org/10.1016/j.jvs.2014.03.244.

[13] Orandi BJ, Selvarajah S, Orion KC, Lum YW, Perler BA, Abularrage CJ. Outcomes of nonelective weekend admissions for lower extremity ischemia. J Vasc Surg. 2014; 60(6):1572-1579.e1. https://doi.org/10.1016/j.jvs.2014.08.091.

[14] Aguayo E, Dobaria V, Nakhla M, et al. National trends and outcomes of inpatient robotic-assisted versus laparoscopic cholecystectomy. Surgery (United States). Mosby Inc.; 2020. p. 625-30. https://doi.org/10.1016/j.surg.2020.06.018.

[15] Van Walraven C, Austin PC, Jennings A, Quan H, Forster AJ. A modification of the elixhauser comorbidity measures into a point system for hospital death using administrative data, Vol 47; 2009.

[16] Using appropriate price indices for expenditure comparisons. https://meps.ahrq. gov/about_meps/Price_Index.shtml. [Accessed 17 January 2021].

[17] Regenbogen SE, Gawande AA, Lipsitz SR, Greenberg CC, Jha AK. Do differences in hospital and surgeon quality explain racial disparities in lower-extremity vascular amputations? Ann Surg. 2009;250(3):424-30. https://doi.org/10.1097/SLA. 0b013e3181b41d53.

[18] Arya S, Binney Z, Khakharia A, et al. Race and socioeconomic status independently affect risk of major amputation in peripheral artery disease. J Am Heart Assoc. 2018;7(2). https://doi.org/10.1161/JAHA.117.007425.

[19] Abou-Zamzam AM, Gomez NR, Molkara A, et al. A prospective analysis of critical limb ischemia: factors leading to major primary amputation versus revascularization. Ann Vasc Surg. 2007;21(4):458-63. https://doi.org/10.1016/j.avsg.2006.12.006.

[20] Schuyler Jones W, Patel MR, Dai D, et al. High mortality risks after major lower extremity amputation in Medicare patients with peripheral artery disease. Am Heart J. 2013;165(5):809-815.e1. https://doi.org/10.1016/j.ahj.2012.12.002.

[21] Cuzick J. A Wilcoxon-type test for trend. Stat Med. 1985;4(1):87-90. https://doi.org/ 10.1002/sim.4780040112.

[22] Tibshirani R. Regression shrinkage and selection via the Lasso. J R Stat Soc Ser B. 1996;58(1):267-88. https://doi.org/10.1111/j.2517-6161.1996.tb02080.x.

[23] Pepe MS. Receiver operating characteristic methodology. Statistics in the 21st century. CRC Press; 2001. p. 60-6. https://doi.org/10.2307/2669554.

[24] Posada D, Buckley TR. Model selection and model averaging in phylogenetics: advantages of Akaike information criterion and Bayesian approaches over likelihood ratio tests. Syst Biol. 2004;53(5):793-808. https://doi.org/10.1080/10635150490522304.

[25] Soden PA, Zettervall SL, Curran T, et al. Regional variation in patient selection and treatment for lower extremity vascular disease in the Vascular Quality Initiative. Journal of Vascular Surgery. Mosby Inc.; 2017. p. 108-18. https://doi.org/10.1016/j. jvs.2016.06.105.

[26] Shishehbor MH, White CJ, Gray BH, et al. Critical limb ischemia: an expert statement. J Am Coll Cardiol. 2016;68(18):2002-15. https://doi.org/10.1016/j.jacc.2016.04.071.

[27] Rudofker EW, Hogan SE, Armstrong EJ. Preventing major amputations in patients with critical limb ischemia. Curr Cardiol Rep. 2018;20(9):1-7. https://doi.org/10. 1007/s11886-018-1019-2.
[28] Goodney PP, Holman K, Henke PK, et al. Regional intensity of vascular care and lower extremity amputation rates. Journal of Vascular Surgery. Mosby Inc; 2013. p. 1471-1480.e3. https://doi.org/10.1016/j.jvs.2012.11.068.

[29] Jones WS, Patel MR, Dai D, et al. Temporal trends and geographic variation of lowerextremity amputation in patients with peripheral artery disease: results from U.S. Medicare 2000-2008. J Am Coll Cardiol. 2012;60(21):2230-6. https://doi.org/10. 1016/j.jacc.2012.08.983.

[30] Minc SD, Goodney PP, Misra R, Thibault D, Smith GS, Marone L. The effect of rurality on the risk of primary amputation is amplified by race. Journal of Vascular Surgery. Mosby Inc.; 2020. p. 1011-7. https://doi.org/10.1016/j.jvs.2019.10.090.

[31] Lucas FL, Stukel TA, Morris AM, Siewers AE, Birkmeyer JD. Race and surgical mortality in the United States. Ann Surg. 2006;243(2):281. https://doi.org/10.1097/01.SLA. 0000197560.92456 .32 .

[32] Selvarajah S, Black JH, Haider AH, Abularrage CJ. Racial disparity in early graft failure after infrainguinal bypass. J Surg Res. 2014;190(1):335-43. https://doi.org/10.1016/ j.jss.2014.04.029.

[33] Durazzo TS, Frencher S, Gusberg R. Influence of race on the management of lower extremity ischemia: revascularization vs amputation. JAMA Surg. 2013;148(7): 617-23. https://doi.org/10.1001/jamasurg.2013.1436.

[34] Holman KH, Henke PK, Dimick JB, Birkmeyer JD. Racial disparities in the use of revascularization before leg amputation in Medicare patients. J Vasc Surg. 2011;54(2): 420-426.e1. https://doi.org/10.1016/j.jvs.2011.02.035.

[35] Soden PA, Zettervall SL, Deery SE, et al. Black patients present with more severe vascular disease and a greater burden of risk factors than white patients at time of major vascular intervention. J Vasc Surg. 2018;67(2):549-556.e3. https://doi.org/ 10.1016/j.jvs.2017.06.089.

[36] Farber A, Eberhardt RT. The current state of critical limb ischemia: a systematic review. JAMA Surg. 2016;151(11):1070-7. https://doi.org/10.1001/jamasurg.2016. 2018.

[37] Armstrong EJ, Wu J, Singh GD, et al. Smoking cessation is associated with decreased mortality and improved amputation-free survival among patients with symptomatic peripheral artery disease. J Vasc Surg. 2014;60(6):1565-71. https://doi.org/10.1016/ j.jvs.2014.08.064.

[38] Chung J, Timaran DA, Modrall JG, et al. Optimal medical therapy predicts amputation-free survival in chronic critical limb ischemia. Journal of Vascular Surgery. Mosby; 2013. p. 972-80. https://doi.org/10.1016/j.jvs.2013.03.050.

[39] Murphy TP, Cutlip DE, Regensteiner JG, et al. Supervised exercise versus primary stenting for claudication resulting from aortoiliac peripheral artery disease: sixmonth outcomes from the claudication: exercise versus endoluminal revascularization (CLEVER) study. Circulation. 2012;125(1):130-9. https://doi.org/10.1161/ CIRCULATIONAHA.111.075770.

[40] Mokwatsi GG, Schutte AE, Kruger R. Ethnic differences regarding arterial stiffness of 6-8-year-old black and white boys. J Hypertens. 2017;35(5):960-7. https://doi.org/ 10.1097/HJH.0000000000001267.

[41] Kruger R, Schutte R, Huisman HW, et al. Associations between reactive oxygen species, blood pressure and arterial stiffness in black South Africans: the SABPA study. Hum Hypertens. 2012;26(2):91-7. https://doi.org/10.1038/jhh.2010.134.

[42] Schutte AE, Huisman HW, Schutte R, et al. Arterial stiffness profiles: investigating various sections of the arterial tree of African and Caucasian people. Clin Exp Hypertens. 2011;33(8):511-7. https://doi.org/10.3109/10641963.2011.561897.

[43] Illig KA. Why do nonwhite patients undergo amputation more commonly than white patients? JAMA Surg. 2013;148(7):623. https://doi.org/10.1001/jamasurg. 2013.1450 . 